\section{Ocular toxicity in low-dose tamoxifen: a prospective study}

\begin{abstract}
Purpose To look at the incidence, symptomatology, course and reversibility of low-dose tamoxifen ocular toxicity. Methods Sixty-five women with breast cancer, on tamoxifen oral therapy ( $20 \mathrm{mg} /$ day $)$, and a totally normal eye examination, were prospectively followed up. A full ophthalmic evaluation was done every 6 months, for a median of 30 months (range 4-79 months). Any sign of toxicity in the cornea, lens, retina or optic nerve was looked for, whether associated with a change in visual acuity or not. Results Ocular toxicity was documented in 8 patients, giving an incidence of $12 \%$. Seven patients had keratopathy in the form of subepithelial deposits, whorls and linear opacities. Three of these patients had a concurrent symptomatic bilateral pigmentary retinopathy that warranted discontinuation of therapy. One patient developed bilateral optic neuritis that left her with optic nerve pallor and a decrease in vision. The patients who had the toxicity had a significantly higher tamoxifen cumulative dose $(p=0.03)$, and were longer on treatment $(p=0.04)$, than the nonaffected ones. The keratopathy changes were reversible upon discontinuation of the drug. Conclusion Prompt reporting of symptoms and yearly ophthalmic examinations are mandatory in patients on tamoxifen to detect
\end{abstract} toxic effects while these are still reversible.

Key words Breast cancer, Keratopathy, Retinopathy, Tamoxifen

Tamoxifen is a triphenylethylene non-steroid oestrogen antagonist. Alone and in combination with other forms of treatment it is used in cases of disseminated breast carcinomas, especially the oestrogen-dependent ones, and as adjuvant post-operative therapy. It acts through interfering with the binding of oestradiol to its target tissues via depletion of cytoplasmic receptors and competitive inhibition at the receptor site. ${ }^{1}$

Its efficacy and low level of adverse effects made tamoxifen the hormonal therapy of choice. The systemic side-effects with the standard dose of 10-20 mg twice a day are
BAHA' N. NOUREDDIN, MUHIEDDIN SEOUD, ZIAD BASHSHUR, ZIAD SALEM, ALI SHAMSEDDIN, ALI KHALIL

limited to headache, nausea, hot flushes, mild fluid retention and minimal modifications in blood cell counts. ${ }^{2,3}$ A definite increase in the incidence of endometrial cancer has also been reported. ${ }^{3,4}$

Tamoxifen ocular toxicity was first reported in 1978 by Kaiser-Kupfer in 4 patients who had concurrent keratopathy and retinopathy. ${ }^{5}$ These patients were on high-dose therapy of $200 \mathrm{mg} /$ day. Similarly, in 1981, a patient on a high dose of $180 \mathrm{mg}$ /day was reported by McKeown et al. ${ }^{6}$ to have bilateral retinopathy. Despite the decrease in the recommended dose of tamoxifen, retinopathy was reported in patients on $40 \mathrm{mg} /$ day, $^{7,8}$ and later in patients on 20 mg/day. ${ }^{9-12}$ This toxicity was, however, reversible in the majority of cases. Optic neuritis was also reported - first by Pugesgaard et al. ${ }^{13}$ then by Ashford et al. ${ }^{14}$ and lately by Therssen et al. ${ }^{15}$ - in patients on low-dose tamoxifen.

In addition to the case reports, several authors have used cross-sectional studies ${ }^{9,15-18}$ to look at the prevalence of ocular toxicity. This ranged from $1.5 \%{ }^{18}$ to $11.8 \%$, ${ }^{9}$ with one study finding no toxicity among 79 patients and 115 controls. $^{17}$

To date, the study by Palvidis et al. ${ }^{19}$ has been the only one to prospectively investigate the incidence and course of ocular toxicity in low-dose tamoxifen treatment ( $20 \mathrm{mg}$ daily) over a median duration of 25 months. The incidence was $6.3 \%$ and retinopathy was the main finding. In their review of all published case reports, clinical series and trial data, Nayfield and Gorin ${ }^{20}$ concluded that, despite its being rare, the potential ocular toxicity of tamoxifen warrants appropriate surveillance and prompt investigation of ocular complaints.

The aim of our study was to look prospectively at the incidence, symptomatology, course and reversibility of low-dose tamoxifen ocular toxicity in 65 patients.

\section{Materials and methods}

All patients with breast cancer receiving lowdose tamoxifen $20 \mathrm{mg} /$ day (10 $\mathrm{mg}$ twice a day) and treated by the co-authors (medical and surgical oncologists) were offered the chance to be included in the study. On average 1 in 3

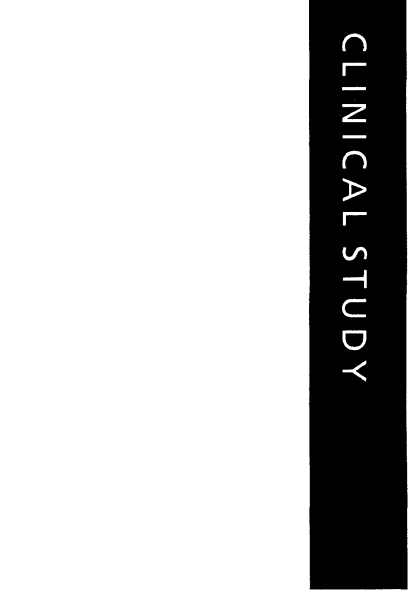

B.N. Noureddin

Z. Bashshur

Department of

Ophthalmology

American University of

Beirut

Beirut, Lebanon

M. Seoud

Z. Salem

A. Shamseddin

A. Khalil

Department of Gynecologic

Oncology

American University of

Beirut

Beirut, Lebanon

Baha' N. Noureddin, MD 850 Third Avenue,

18th floor

New York, NY 10022, USA

Tel: +1 (961) 1 350000/ 8989

Fax: +1 (961) 1744464

e-mail: bndean@aub.edu.lb

Received: 7 April 1999

Accepted in revised form:

12 July 1999 
Table 1. Staging of breast cancer in the study patients

\begin{tabular}{ccc}
\hline $\begin{array}{c}\text { Stage of } \\
\text { breast cancer }\end{array}$ & $\begin{array}{c}\text { No. of } \\
\text { patients }\end{array}$ & $\begin{array}{c}\text { Percentage of } \\
\text { patients }\end{array}$ \\
\hline I & $6 / 31$ & $19 \%$ \\
II & $16 / 31$ & $52 \%$ \\
III & $8 / 31$ & $26 \%$ \\
IV & $1 / 31$ & $3 \%$ \\
\hline
\end{tabular}

patients accepted, with 65 patients being enrolled between 1992 and 1996. The project was submitted and approved by the university's Internal Review Board and its Ethics Committee on Human Research. All patients signed an informed consent form, all attended the ophthalmology visits and none was lost to follow-up. Five patients were excluded from the study because of different ocular conditions. The stage of their disease is listed in Table 1; it follows the International Union Against Cancer and the American Joint Committee on Cancer TNM staging:

Stage I: Tumour $<2 \mathrm{~cm}$ with negative lymph nodes and no distant metastasis.

Stage II: Tumour $>2 \mathrm{~cm}$ but $<5 \mathrm{~cm}$ with or without fixation to pectoralis with no lymph node metastasis or with axillary fixed nodes, and no distant metastasis.

Stage III: Tumour $<2 \mathrm{~cm}$ or $>5 \mathrm{~cm}$ with or without fixation to chest wall with or without axillary fixed nodes with or without supraclavicular nodes.

Stage IV: Any size lesion or lymph node metastasis with distant metastasis.

Table 2 describes the different modes of therapy received. Chemotherapy was given in 29 patients and consisted of FAC in 10 (5-fluorouracil, adriamycin and cyclophosphamide) and of CMF in 19

(cyclophosphamide, methotrexate and 5-fluorouracil), usually for six cycles following surgery. Some of these patients were already on tamoxifen therapy. However, they were included as their eye examination was normal at the initial screening visit. The mean age was 51.9 years ( \pm 10.7 years) with a median of 54 years and a range of 21-73 years. The mean duration of tamoxifen therapy was 31.6 months (+16.0 months) with a median of 30 months and a range of 4-79 months.
Table 2. Type of breast cancer therapy in the study patients

\begin{tabular}{lcc}
\hline Type of therapy & $\begin{array}{c}\text { No. of } \\
\text { patients }\end{array}$ & $\begin{array}{c}\text { Percentage of } \\
\text { patients }\end{array}$ \\
\hline Modified radical mastectomy & $33 / 41$ & $81 \%$ \\
Lumpectomy & $7 / 41$ & $17 \%$ \\
None & $1 / 41$ & $2 \%$ \\
Chemotherapy & $29 / 42$ & $69 \%$ \\
\hline
\end{tabular}

After ensuring a normal initial examination, and the absence of ocular complaints, the patients were assessed regularly at 6 month intervals by the same examiner (B.N.). The examination consisted of the following:

Corrected visual acuity.

Goldmann applanation tonometry.

Colour vision testing with the Ishihara pseudoisochromatic colour plates.

Slit-lamp examination with emphasis on corneal findings: opacities, epithelial, endothelial changes and oedema. Lenticular changes were also stressed, and anterior segment photographs were taken when any change was suspected.

Dilated fundus examination with emphasis on the morphology of the optic nerve head, macula and fovea. Subtle retinal pigmentary changes were noted, and coloured fundus photographs taken if necessary.

Patients with cataracts, glaucoma, stage IV trachoma, diabetes, arterial hypertension, drug intake, and any significant ocular disease were excluded from the study.

\section{Results}

Ocular toxicity was documented in 8 patients, giving an incidence of $12 \%$. The toxicity was in the form of an isolated keratopathy in 4 patients, concurrent keratopathy and retinopathy in 3 and optic neuritis in 1 patient (Table 3). The isolated keratopathy was characterised by white to yellow linear subepithelial opacities always inferiorly and below the visual axis. The orientation of the lines was horizontal in the first 2 patients and oblique in the other 2. The 4 patients' ages were $49,34,65$ and 54 years, respectively. The duration of tamoxifen treatment at the onset of the corneal findings was $48,36,18$ and 6 months, while the total dose received was 29.18, 21.88, 10.94 and $3.64 \mathrm{~g}$, respectively (Table 3). The visual acuities in all 4 patients were unchanged from the initial screening visits, and no ocular complaints were reported (Table 4). Consequently, it was decided not to

Table 3. Age, duration of tamoxifen therapy and cumulative dose in the patients with ocular toxicity

\begin{tabular}{|c|c|c|c|c|c|c|}
\hline Patient no. & $\begin{array}{l}\text { Age } \\
\text { (years) }\end{array}$ & $\begin{array}{c}\text { Time on tamoxifen } \\
\text { (months) }\end{array}$ & $\begin{array}{l}\text { Total tamoxifen } \\
\text { dose }(\mathrm{g})\end{array}$ & Keratopathy & Retinopathy & $\begin{array}{l}\text { Optic } \\
\text { neuritis }\end{array}$ \\
\hline 1 & 49 & 48 & 29.18 & + & - & - \\
\hline 2 & 34 & 36 & 21.88 & + & - & - \\
\hline 3 & 65 & 18 & 10.94 & + & - & - \\
\hline 4 & 54 & 6 & 3.64 & + & - & - \\
\hline 5 & 50 & 30 & 18.24 & + & + & - \\
\hline 6 & 44 & 24 & 14.60 & + & + & - \\
\hline 7 & 56 & 9 & 5.47 & + & + & - \\
\hline 8 & 44 & 4 & 2.40 & - & - & + \\
\hline
\end{tabular}


Table 4. Visual acuities of the affected patients at the onset of the findings, during the study and at the final examination

\begin{tabular}{|c|c|c|c|c|c|c|c|}
\hline \multirow{2}{*}{$\begin{array}{c}\text { Patient } \\
\text { no. }\end{array}$} & \multirow[b]{2}{*}{ Toxicity } & \multicolumn{2}{|c|}{$\begin{array}{c}\text { Initial visual } \\
\text { acuity } \\
\end{array}$} & \multicolumn{2}{|c|}{$\begin{array}{l}\text { Interim visual } \\
\text { acuity } \\
\end{array}$} & \multicolumn{2}{|c|}{$\begin{array}{c}\text { Final visual } \\
\text { acuity }\end{array}$} \\
\hline & & $\mathrm{R}$ & $\mathrm{L}$ & $\mathrm{R}$ & $\mathrm{L}$ & $\mathrm{R}$ & $\mathrm{L}$ \\
\hline 1 & K & $20 / 20$ & $20 / 20$ & $20 / 20$ & $20 / 20$ & $20 / 20$ & $20 / 20$ \\
\hline 2 & $\mathrm{~K}$ & $20 / 20$ & $20 / 20$ & $20 / 20$ & $20 / 20$ & $20 / 20$ & $20 / 20$ \\
\hline 3 & K & $20 / 20$ & $20 / 20$ & $20 / 20$ & $20 / 20$ & $20 / 20$ & $20 / 20$ \\
\hline 4 & K & $20 / 20$ & $20 / 20$ & $20 / 20$ & $20 / 20$ & $20 / 20$ & $20 / 20$ \\
\hline 5 & $\mathrm{~K} / \mathrm{R}$ & $20 / 20$ & $20 / 20$ & $20 / 40$ & $20 / 40$ & $20 / 40$ & $20 / 40$ \\
\hline 6 & $\mathrm{~K} / \mathrm{R}$ & $20 / 20$ & $20 / 20$ & $20 / 25$ & $20 / 25$ & $20 / 25$ & $20 / 25$ \\
\hline 7 & $\mathrm{~K} / \mathrm{R}$ & $20 / 20$ & $20 / 20$ & $20 / 20$ & $20 / 20$ & $20 / 20$ & $20 / 20$ \\
\hline 8 & ON & $20 / 20$ & $20 / 20$ & $20 / 40$ & $20 / 30$ & $20 / 80$ & $20 / 40$ \\
\hline
\end{tabular}

$\mathrm{R}$, right eye; $\mathrm{L}$, left eye; $\mathrm{K}$, keratopathy, $\mathrm{R}$, retinopathy, $\mathrm{ON}$, optic neuritis.

discontinue tamoxifen and the patients were watched very closely for any symptom or increase in the corneal findings. The last follow-up showed no increase in the number or opaqueness of the subepithelial lines, and the visual acuities have been maintained.

Three patients developed concurrent keratopathy and retinopathy. They were 50, 44 and 56 years of age, respectively. The duration of tamoxifen treatment until the appearance of the clinical findings was 30, 24 and 9 months, respectively. The total dose as a result was 18.24 , 14.60 and $5.47 \mathrm{~g}$, respectively (Table 3). The first patient presented with blurring of vision in both eyes, and her visual acuities were 20/40 and 20/40 compared with $20 / 20$ at the initial screening visit (Table 4). The anterior segment examination showed bilateral corneal subepithelial whorl-like opacities inferior to the visual axis. The posterior pole showed paramacular yellowish refractile crystals associated with cystoid macular oedema.

Fluorescein angiography showed hyperfluorescence in the area of the crystals, and the late phase documented the cystoid oedema in the macula. Tamoxifen was stopped and the visual acuities were still 20/40 in each eye 6 months later. There was no increase in the number and extent of the retinal crystals and the fluorescein angiographic findings were unchanged. On the other hand, the corneal findings became much less pronounced.

The second patient had no significant symptoms. However, the visual acuities were $20 / 25$ in either eye compared with $20 / 20$ during the initial visit. The corneas showed subtle subepithelial bilateral white inferior deposits. Fine granular changes at the level of the retinal pigment epithelium were shown by fundoscopy to surround the macula. The optic nerve was normal, and fluorescein angiography showed hyperfluorescence in the paramacular area. Tamoxifen therapy was discontinued, and the follow-up 6 months later showed persistence of the retinal findings but not the corneal ones. The visual acuities remained stable at $20 / 25$, and fluorescein angiography showed less hyperfluorescence but the findings were essentially unchanged. Similarly, the third patient had no visual symptoms and her visual acuity was 20/20 in either eye. However, at a routine follow-up visit she was found to have bilateral thin brownish subepithelial streaks of corneal opacification inferior to the visual axis. Retinal examination disclosed a few refractile crystals surrounding the macula of either eye. The optic disc and retinal vessels were normal, and there was no macular oedema. Fluorescein angiography showed only minimal hyperfluorescence in the areas where the crystals were found. Despite the presence of these minimal findings it was decided to discontinue tamoxifen. Six months later the corneal findings were minimal, and there was no increase in the number of the retinal crystals and no decrease in visual acuity. Similarly, the fluorescein angiographic findings remained essentially the same.

The patient who developed optic nerve head pallor was 44 years old and had a normal initial eye examination. After 4 months of tamoxifen treatment (total dose $2.40 \mathrm{~g}$ ) she presented with blurring of vision in both eyes (right more than left). Her visual acuities had become 20/40 and 20/30 respectively. Her intraocular pressures and anterior segments were normal and she had no pain on ocular movements. The fundus examination showed bilateral blurring of the disc margins together with mild capillary congestion and a few diffuse haemorrhages superiorly. There were no exudates and both macular areas were normal.

Fluorescein angiography confirmed the clinical findings of disc oedema, and late leakage around the nerve head was documented. Systemic investigations and magnetic resonance imaging of the brain were negative for metastasis, cerebral or orbital abnormalities. Tamoxifen was discontinued, and the clinical examination after 6 weeks showed resolution of the haemorrhages and disc swelling, but this was replaced with progressive pallor of the nerve head and her latest visual acuities were 20/80 and $20 / 40$ respectively.

To try to investigate the reason behind the high incidence of ocular toxicity in our study we compared patients who had the toxicity with those who did not (Table 5). There was no difference in age between the two groups $(p=0.3)$, but there was a statistically significant

Table 5. Comparison of the mean ages, duration of therapy and total dose of patients affected or not affected by ocular toxicity

\begin{tabular}{|c|c|c|c|}
\hline & $\begin{array}{l}\text { Affected } \\
\text { patients } \\
(n=8)\end{array}$ & $\begin{array}{l}\text { Non-affected } \\
\text { patients } \\
(n=57)\end{array}$ & $\begin{array}{c}P \\
\text { value }\end{array}$ \\
\hline \multicolumn{4}{|c|}{ Age (years) } \\
\hline Mean & $53.0 \pm 10.8$ & $49 \pm 8.9$ & 0.3 \\
\hline Median & 55 & 48 & \\
\hline \multicolumn{4}{|c|}{ Duration of tamoxifen therapy (months) } \\
\hline Mean & $30.2 \pm 14.0$ & $42 \pm 12.8$ & 0.04 \\
\hline Median & 30 & 42 & \\
\hline Range & $4-57$ & $18-49$ & \\
\hline \multicolumn{4}{|c|}{ Total dose (g) } \\
\hline Mean & $28.4 \pm 8.4$ & $25.4 \pm 13.7$ & 0.03 \\
\hline Median & 18 & 25.2 & \\
\hline Range & $2.4-34.2$ & $10.8-47.4$ & \\
\hline
\end{tabular}


difference in the duration of therapy with tamoxifen $(p=0.04)$, and in the total cumulative dose of the drug $(p=0.03)$ (comparison of means with Student's $t$-test).

\section{Discussion}

Despite reports of the successful use of tamoxifen in the treatment of ovarian cancer, pancreatic cancer and malignant melanoma, ${ }^{21-24}$ its role in breast cancer therapy remains the most important. In addition to its common use in advanced cases, post-operatively in the early stages, it has recently been tested in high-risk women. ${ }^{25}$ The above widespread use of tamoxifen has been made possible by the rarity of any systemic sideeffects. ${ }^{3}$

Ocular toxicity, on the other hand, since the reports first of Kaiser-Kupfer ${ }^{5}$ then of McKeown, ${ }^{6}$ have alerted both oncologists and ophthalmologists. The high doses (>180 mg/day) were initially incriminated, but this was shown not to be the case when some patients on the lowdose regimen ( $20 \mathrm{mg} /$ day) were reported to have ocular side effects. ${ }^{9-12}$ The most frequent toxic effect was retinopathy, followed by keratopathy, and so far 3 cases of optic neuritis have been reported. ${ }^{13-15}$ A single crosssectional controlled study ${ }^{17}$ showed no toxicity in 79 patients on low-dose treatment. However, no patient has received at conventional dosage levels a cumulative amount known to be associated with ocular toxicity in high dosage.

The incidence of ocular toxicity in our study was $12 \%$. This is a relatively high figure compared with the $6.3 \%$ in Palvidis' et al. prospective study. ${ }^{19}$ Another dissimilarity from the literature is the high rate of keratopathy, which occurred in the vast majority of affected cases (Table 3). However, despite their clinical appearance, tamoxifeninduced keratopathies were not responsible for any deterioration in vision, as the patients (patients 1, 2, 3 and 4) maintained their initial visual acuities, and the medication was not discontinued. It is interesting to note that patient 4 had her keratopathy after only 6 months of therapy with the low total dose of $3.64 \mathrm{~g}$ (Table 3), thus putting in doubt the belief that toxicity can not occur after a short time on the low-dose regimen. We can not speculate on the high rate of keratopathy in our study. The latter, there being no controls, included only patients who had a completely normal initial ocular test, and the former were assessed by the same examiner for the whole period of the study. All patients with even minimal ocular findings or complaints were excluded to avoid any confusion with a pre-existing eye condition. Structurally, the subepithelial linear opacities were very similar to those encountered in chloroquine- and amiodarone-induced keratopathies. ${ }^{26}$

All our retinopathy cases (patients 5,6 and 7) had a concurrent keratopathy similar to the isolated ones in the first four patients. The clinical picture of paramacular refractile crystals associated with macular oedema in 1 case (patient 5), and no oedema in the other 2 (patients 6 and 7), has been consistently reported in the literature. ${ }^{19,20}$ The visual acuity was affected in 2 patients (patients 5 and 6) but not in the third (patient 7), and tamoxifen therapy was stopped. It was also noted that the third patient (patient 7) had had tamoxifen for 9 months only, with the total dose of $5.47 \mathrm{~g}$. Unlike the corneal findings in these 3 patients, the retinopathy changes and their effects on vision (when present) did not seem to be reversible upon discontinuing tamoxifen. This is in agreement with the literature, where retinopathy was irreversible at times ${ }^{7,8}$ and reversible at others. $^{10,11,12,19}$

The irreversibility of the high-dose retinal toxicity was thought to be secondary to axonal degeneration that was demonstrated by Kaiser-Kupfer et al. ${ }^{27}$ in a histopathological study. The latter showed the retinal lesions to be confined to the nerve fibre and inner plexiform layers and to be intra- and extracellular, in and around the axons. The mechanism by which tamoxifen induces corneal and retinal toxicity has been likened to that of cationic amphiphilic drugs. ${ }^{28,29}$ These include chloroquine, amiodarone, chlorpromazine, triparanol, quinacrine, thioridazine and tilorone, which are all structurally similar. They have a hydrophobic moiety and a positively charged hyrophilic side-chain on the same molecule. They form tight but reversible bonds with polar lipids resulting in intracellular and intralysosomal lipidosis. $2,17,20$

The greatest effect on the visual acuity was in the patient who developed optic neuritis in both eyes after receiving tamoxifen for 4 months (total dose $2.40 \mathrm{~g}$ ). Therapy was stopped directly, and there was reversal of the nerve oedema, but moderate pallor/atrophy had already resulted. Pugesgaard and von Eyben ${ }^{13}$ reported the first case of optic neuritis in a patient on tamoxifen. The total dose was $6 \mathrm{~g}$ after 6 months on therapy, and the patient was left with severe optic atrophy in one eye despite discontinuation of the drug. The second reported case $^{14}$ had the drug only for 3 weeks, and the neuritis was reversible with no sequelae, while the third ${ }^{15}$ was thought to have a retrobulbar process after taking the medication for 3 years. His symptoms and findings were also reversible. In these cases, as well as in ours, a causeand-effect relationship is difficult to demonstrate. However, the absence of any other abnormality, and the reversal of symptoms in 2 of the patients ${ }^{14,15}$ after stopping the drug, preserve the possibility. The mechanism by which tamoxifen might cause optic neuritis is unknown, and histopathological studies are not available. The most plausible suggestion, however, is for the drug to cross the blood-brain and blood-retina barriers, though tamoxifen could not be detected in the cerebrospinal fluid.

In conclusion, our study joins that of Vinding and Nielsen ${ }^{9}$ and Palvidis et al. ${ }^{19}$ in finding a high incidence of tamoxifen ocular toxicity, despite the benign nature of the isolated keratopathies. As a result, there is a need for a detailed ophthalmic evaluation in patients before starting tamoxifen therapy, followed by clear instructions to report even subtle visual symptoms. Finally, yearly evaluations seem to be in order as some of the changes are initially asymptomatic. 


\section{References}

1. Clark JH, Peck EJ Jr, Anderson JN. Oestrogen reception and antagonism of steroid hormone action. Nature 1974;251:446-8.

2. Imperia PS, Lazarus HM, Lass J. Ocular complications of systemic cancer chemotherapy. Surv Ophthalmol 1989;34:219-30.

3. Sananes S, Khairallah T, Touboul E, Salat-Baroux J, Uzan S. A surveillance of patients treated with tamoxifen. Presse Med 1996;25:499-502.

4. Seoud M, Johnson J, Weed JC. Gynecologic tumors in tamoxifen-treated women with breast cancer. Obstet Gynaecol 1993;82:165-9.

5. Kaiser-Kupfer MI, Lippman ME. Tamoxifen retinopathy. Cancer Treat Rep 1978;62:315-20.

6. McKeown CA, Swart ZM, Bloom J, Maggiano JM. Tamoxifen retinopathy. Br J Ophthalmol 1981;65:177-9.

7. Gerner EW. Ocular toxicity of tamoxifen. Ann Ophthalmol 1989;21:420-3.

8. Bentley CR, Davies G, Aclimandos WA. Tamoxifen retinopathy: a rare but serious complication. BMJ 1992;304:495-6.

9. Vinding T, Nielsen NV. Retinopathy caused by treatment with tamoxifen in low dose. Acta Ophthalmol (Copenh) 1983;61:45-50.

10. Griffiths M. Tamoxifen retinopathy at low dosage. Am J Ophthalmol 1987;104:185-6.

11. Chang T, Gonder JR, Ventresco MR. Low-dose tamoxifen retinopathy. Can J Ophthalmol 1992;27:148-9.

12. Chern S, Danis R. Retinopathy associated with low-dose tamoxifen. Am J Ophthalmol 1993;116:372-3.

13. Pugesgaard T, Von Eyben FE. Bilateral optic neuritis evolved during tamoxifen treatment. Cancer 1986;58:383-6.

14. Ashford AR, Done VI, Tiwari RP, Garett TJ. Reversible ocular toxicity related to tamoxifen therapy. Cancer 1988;61:33-5.

15. Thersson R, Jansen E, Leys A, Rutten J, Meyskens J. Screening for tamoxifen ocular toxicity: a prospective study. Eur J Ophthalmol 1995;5:230-4.
16. Beck M, Mills PV. Ocular assessment of patients treated with tamoxifen. Cancer Treat Rep 1979;63:1833-4.

17. Longstaff S, Sigurdsson H, O'Keeffe M, Ogston S, Preece P. A controlled study of the ocular effects of tamoxifen in conventional dosage in the treatment of breast carcinoma. Eur J Cancer Clin Oncol 1989;25:1805-8.

18. Heier J, Dragoo R, Enzenauer R, Waterhouse W. Screening for ocular toxicity in asymptomatic patients treated with tamoxifen. Am J Ophthalmol 1994;117:772-5.

19. Palvidis NA, Petris C, Braissoulis, et al. Clear evidence that long-term, low dose tamoxifen treatment can induce ocular toxicity. Cancer 1992;69:2961-4.

20. Nayfield SG, Gorin MB. Tamoxifen-associated eye disease: a review. J Clin Oncol 1996;14:1018-26.

21. Schwartz PE, Keating G, MacLusky N. Tamoxifen therapy for advanced ovarian cancer. Obstet Gynecol 1982;59:583-8.

22. Crowson MC, Dorrel A, Rolfe EB, Fielding JWL. A phase II study to evaluate tamoxifen in pancreatic adenocarcinoma. Eur J Surg Oncol 1986;12:335-6.

23. Tonnesen K, Kamp-Jensen M. Antiestrogen therapy in pancreatic carcinoma: a preliminary report. Eur J Surg Oncol 1986;12:69-70.

24. Meyskens FL Jr, Voakes JB. Tamoxifen in metastatic malignant melanoma. Cancer Treat Rep 1980;64:171-3.

25. Kramer BS, Brawley OW, Nayfield S, et al. NCI studies in primary prevention of breast and prostatic cancer. Cancer Res Ther Control 1993;3:203-11.

26. Lullman H, Lullman-Rauch R, Wasserman O. Drug induced phospholipidoses. Crit Rev Toxicol 1975;4:185-218.

27. Kaiser-Kupfer MI, Kupfer C, Rodrigues MM. Tamoxifen retinopathy: a clinicopathologic report. Ophthalmology 1981;88:89-93.

28. Lullman H, Lullman-Rauch R. Tamoxifen induced generalized lipidosis in rats subchronically treated with high doses. Toxicol Appl Pharmacol 1981;61:138-46.

29. Drenckhahn D, Lullman-Rauch R. Drug induced retinal lipidosis: differential susceptibilities of pigment epithelium and neuroretina toward several amphilic cationic drugs. Exp Mol Pathol 1978;28:360-71. 